\title{
Surgical Treatment of Cardiac Myxomas: A 23-Case Experience
}

\author{
Ali Kemal Gür ${ }^{1}$ Mehmet Coşkun Aykaç²

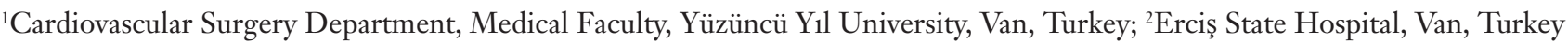

\section{ABSTRACT}

Objective: Although seen rarely compared to all tumors, cardiac tumors are tumors which may have a mortal course with possible complications. The most common cardiac tumor in adults is myxoma with its benign character. The results of cardiac tumors resected with open cardiac surgery in our center are reported in this study.

Materials and Methods: Twenty-three cardiac tumor patients electively operated on in our clinic between January 2010 and August 2017 were retrospectively included in the study. Information of the patients participating in the study were registered. The patients were between 25 and 67 years of age, and 18 were female $(72.3 \%)$, and 5 were male $(21.7 \%)$. The average age of the patients was $42.1 \pm 8.9$ years. Echocardiography was used for diagnosis in all patients. There was no common complaint for the patients, with the complaints changing according to tumor location. All patients were operated on by means of cardiopulmonary bypass with aortic crossclamp and bicaval cannulation. Preoperative demographical characteristics and perioperative and postoperative data were registered for the patients and were evaluated statistically.

Results: Nineteen of the tumors $(82.6 \%)$ were in the left atrium, and 4 were $(17.4 \%)$ in the right atrium. Diameter of the tumors changed between $2.5 \times 1.5$ and $8.5 \times 6.5 \mathrm{~cm}$. The tumoral structure was resected together with the solid tissue located in its root in all patients operated on. Pericardial patch was used for $11(47.8 \%)$, and primary closure was used for $12(51.2 \%)$ of the defects. Early and late mortality was not observed in any patient.

Conclusion: To prevent possible complications of cardiac myxomas, they need to be resected together with the surrounding healthy tissue as soon as possible after the diagnosis. Cardiac myxomas can be operated on with a tolerable operation risk. Echocardiography should be made annually for any possible relapse after operation.

\section{INTRODUCTION}

Myxoma is the most common primary cardiac tumor in adults. They can be observed in all chambers of the heart

Received February 11, 2018; received in revised form March 12, 2018 ; accepted April 27, 2018

Correspondence: Ali Kemal Gür, Yüzüncü Yıl University Medical Faculty Cardiovascular Surgery Department, Van, Turkey; Cell: +90-536-563-26-71; (email: dralikemal@gmail.com). although they are generally in atriums. The etiology of these tumors seen generally in the interatrial septum is unknown. It is considered that familial factors play an active role (Ying 2016). The $2 \mathrm{p}, 12$, and $17 \mathrm{p}$ chromosomes were reported especially in studies on patients with Carney complex, and it was observed that genetic anomaly played a role (Gur 2012).

Complaints of the patients are correlated with tumor size. If the tumoral structure is small, the patients can be asymptomatic, or common symptoms such as weight loss, weakness, general tiredness, and fever can be observed. Diagnosis can be made during scans of or consultations with these patients. But cardiac complaints such as dyspnea, orthopnea, pulmonary edema, hemoptysis, coughing, and fainting may be observed as the tumoral structure becomes larger (Abu Abeeleh 2017). Embolic incidents may also be observed because of the pieces tearing from these tumoral structures. Peripheral embolismrelated ischemia and cranial embolism-related plegia may be observed. Thus, they should be removed surgically as soon as possible after diagnosis.

Although there are no specific findings in laboratory examination of these tumoral structures, findings such as anemia, C-reactive protein (CRP), and erythrocyte-sedimentation increase may be observed generally (Garatti 2012).

These tumoral structures generally hold on to the tissue they are based on through a small polyp. Low cellular

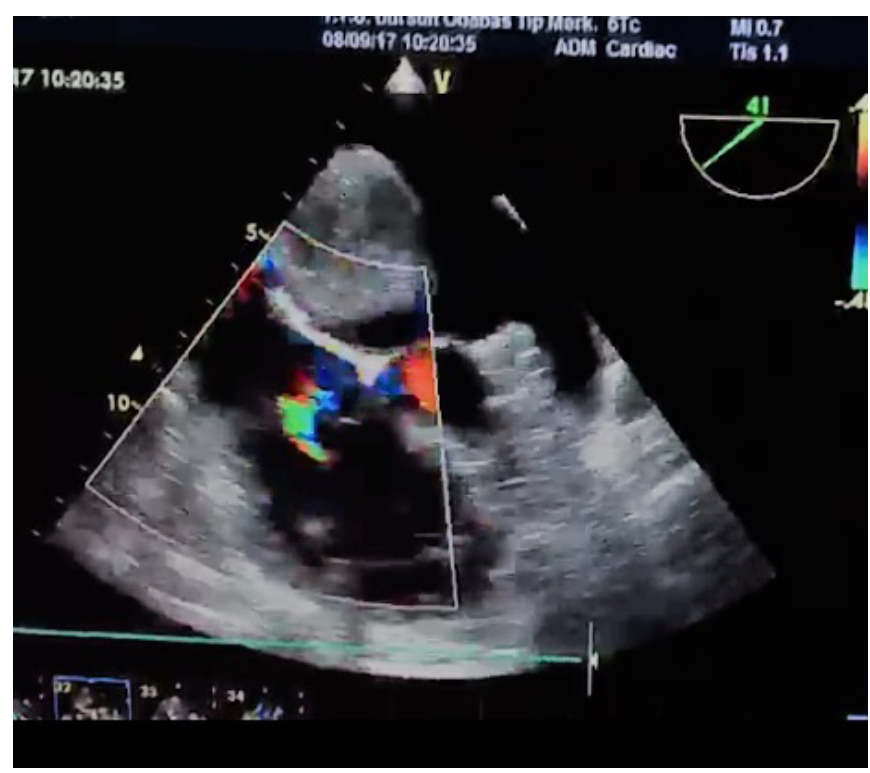

Figure 1. Echocardiography image. 


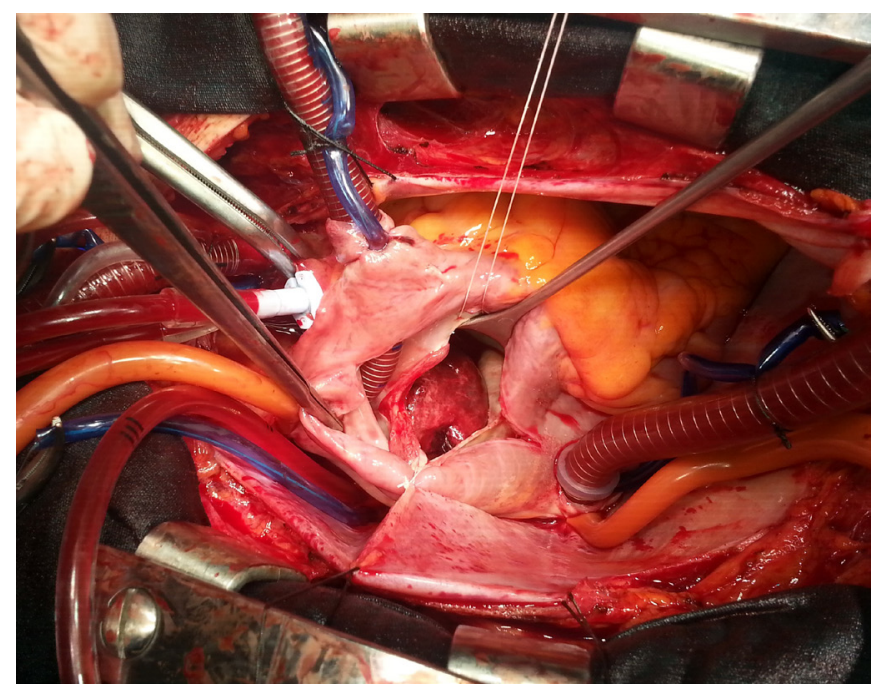

Figure 2. Left atrial myxoma image.

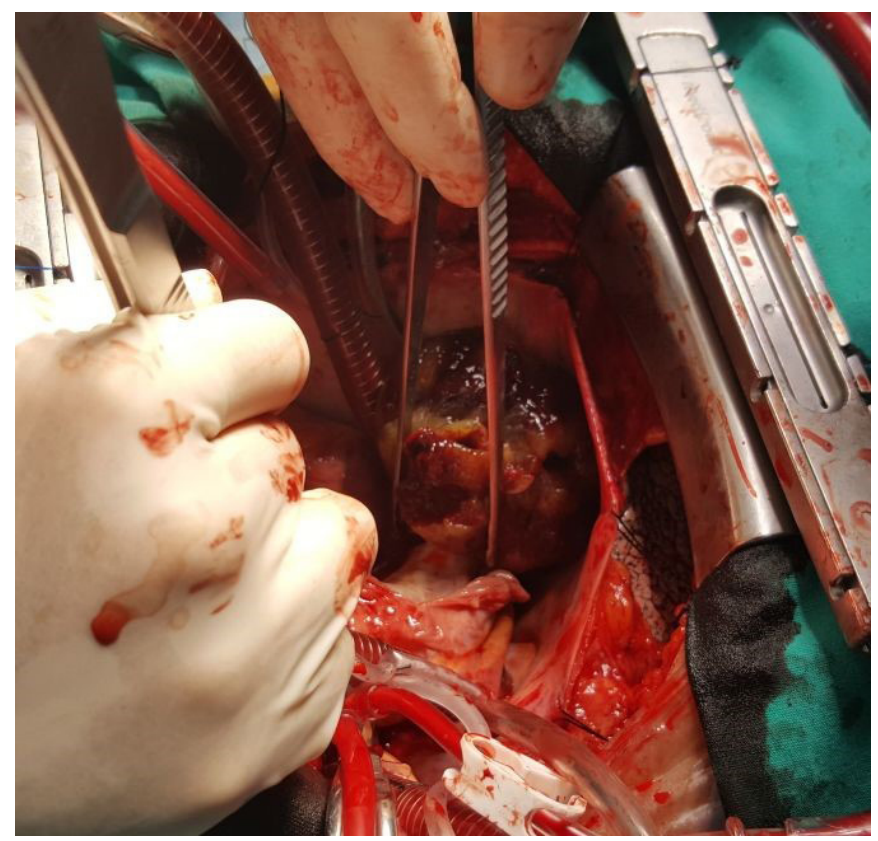

Figure 3. Right atrial myxoma image.

structures are scattered in the mucopolysaccharide matrix in the microscopic structure of these generally jellylike tumors. Thus, attention should be paid not to smash the jellylike structures when one resects during operation.

To see the structure, place, size, and mobility of the tumor, and its connection with cardiac structures, echocardiography, which is the golden standard, is used. Computed tomography can also be used for magnetic resonance imaging. If the patients are over 45 years of age, coronary angiography can be used to show accompanying coronary incidences. Our aim in this study was to present 23 cardiac tumor patients electively operated on between January 2010 and August 2017.
Table 1. Preoperative Clinical and Demographic Characteristics of Patients*

\begin{tabular}{lc} 
Variable & Data, N (23) $\dagger$ \\
\hline Mean age (y) & 42.1 \\
Sex (n/n [male/female]) & $5 / 18$ \\
Average BMI & $2.2 \pm 1.12$ \\
Average mass size (cm) & $3.5 \times 2.5$ \\
HT [n (\%)] & $5(21.7 \%)$ \\
DM [n (\%)] & $2(8.6 \%)$ \\
EF (\%) & $55 \pm 5.8$ \\
Pre-op Hb levels (gr/dL) & $14 \pm 2.4$ \\
Pre-op INR & $1.1 \pm 0.5$ \\
Pre-op platelet levels & $240.000 \pm 40.000$ \\
CRP & $8 \pm 6.8$ \\
Erythrocyte-sedimentation rate $(\mathrm{mm} / \mathrm{h})$ & $16 \pm 8.9$ \\
\hline
\end{tabular}

*HT. (Hipertension) (Patients with arterial blood pressure over 140/90 $\mathrm{mmHg}$ is considered hipertensive for this study)

$\dagger$ Data are given according to the information in each row. All the \pm items indicating “ $\pm S D$

\section{MATERIALS AND METHODS}

Twenty-three patients who were electively operated on, had cardiac myxoma excision in our clinic between January 2010 and December 2017, and had registered information were retrospectively included in the study. Preoperative demographical data of all patients were registered in detail. The patients were between 25 and 67 years of age, and 18 were female $(72.3 \%)$, and 5 were male $(21.7 \%)$. The average age of the patients was 42.1 years. Preoperative demographical data, other risk factors, hypertension (HT), chronic obstructive pulmonary disease (COPD), smoking, hematocrit levels, CRP and erythrocyte-sedimentation rates, aortic cross-clamp (ACC) time, and blood product uses were evaluated for the patients and registered in detail. Diagnosis was made with transthoracic echocardiography in all patients. Preoperative EuroSCORE risk scoring was used for the patients. The right jugular vein was used for central vein catheterization under anesthesia. The left radial artery was used invasively for arterial blood pressure measurement. A complete dose of heparin for cardiopulmonary bypass (CPB) considering the weight was applied after median sternotomy. Aortic and bicaval cannulation based on activated clotting time (ACT) and BSA was performed on the patients. Cardiac arrest was provided with $32^{\circ} \mathrm{C}$ medium degree of hypothermia and antegrade blood cardioplegia. The heart was not manipulated much before locating the crossclamp to prevent embolic incidence. Mass excision was made by opening right atriotomy for the masses on the right side and interatrial septum for those on the left side (Figures 2-3). Tumoral structures especially based on the interatrial septum 
Table 2. Complaints of Patients

\begin{tabular}{lcc}
\hline & $\mathrm{n}$ & $\%$ \\
\hline Asymptomatic & 13 & 56.5 \\
Shortness of breath & 4 & 17.3 \\
Palpitation & 5 & 21.7 \\
Syncope & 3 & 13 \\
Chest pain & 8 & 34.6 \\
Other complaints (fatigue, weakness, weight loss, fever) & 10 & 43.4
\end{tabular}

were excised with a 1-cm tissue from the polypoid structures up to the healthy tissue. Atrial septal defects formed were closed with pericardial patch with 4-0 prolene. Blood gas values of the patients were checked every 30 minutes. Variables such as CPB time (minutes) and cross-clamp time (minutes) were registered and evaluated during the operation.

\section{RESULTS}

Twenty-three patients included in the study were between 25 and 67 years of age and the average age was 42.1.Eighteen of the patients were female $(72.3 \%)$, and 5 were male (21.7\%). Male patients were between 32 and 62 years of age, and their average age was 44.6. Female patients were between 28 and 67 years of age, and the average age was 40.1 years. Among 23 patients, 5 (21.7\%) had diabetes mellitus, 2 (8.6\%) had COPD, and 8 (34.6\%) had hypertension. Preoperative demographical data of the patients are available in Table 1.

Thirteen patients had no complaints $(56.5 \%)$. These patients were detected during the echocardiography made for control due to different causes. Other complaints were dyspnea in $4(17.3 \%)$ patients, tachycardia in 5 patients $(21.7 \%)$, fainting in $3(13 \%)$ patients, chest pain in 8 patients $(34.6 \%)$, and general disease complaints such as weakness, fatigue, and weight loss in 10 patients (43.4\%) (Table 2). Transthoracic echocardiography was used for the diagnosis of all patients. Transesophageal echocardiography was performed on 5 patients to detect the exact place causing valve deficiency. Preoperative coronary angiography was performed on all patients over 45 years of age.

Nineteen of the tumors were in the left atrium of the interatrial septum $(82.6 \%), 3$ were in the right atrium of the interatrial septum (13\%), and 1 was (4.3\%) was on the free wall of right atrium (Table 3). Although the tumor diameter changed between $2.5 \times 1.5$ and $8.5 \times 6.5 \mathrm{~cm}$, the average was $3.5 \times 2.5$ $\mathrm{cm}$. The tumoral structure was resected together with the solid tissue located in its root in all patients operated on. Pericardial patch was used for $11(47.8 \%)$, and primary closure was used for $12(51.2 \%)$ of the defects. Tricuspid Kay annuloplasty was performed on 2 patients with tumors on the right atrium side because they caused severe tricuspid valve deficiency (Figure 4). A patient was taken into revision surgery because of postoperative tamponade. Average ACC time of the patients was found to be $23.6 \pm 15.1$ minutes. Average intensive care hospitalization time was $1.2 \pm 1.6$ days. Postoperative findings
Table 3. Locations of Tumor

\begin{tabular}{lcc}
\hline & $n$ & $\%$ \\
\hline Interatrial septum, left atrial & 19 & 82.6 \\
Interatrial septum, right atrial & 3 & 13.05 \\
Right atrial free wall & 1 & 4.35 \\
& \\
are available in Table 4. Average hospitalization time of the \\
patients was $5.7 \pm 2.6$ days. Histopathological examinations of \\
the patients were reported as showing cardiac myxoma. Early \\
and late mortality was not observed in any patient.
\end{tabular}

\section{DISCUSSION}

Myxomas are mesenchymal-originated benign tumors. The most common primary cardiac tumor in adults is myxoma. In a study by Hoffmeier et al (Hoffmeier 2014), it was reported that myxoma was the most common among cardiac tumors and metastatic tumors followed and that primary malignant cardiac tumors were rare. They can be observed in all chambers of the heart although they can be seen in atriums commonly. The etiology of these tumors seen generally in the interatrial septum is not completely known. It is considered to be caused by stromal cells with a capacity to distinguish endothelium lines, and familial factors also play an active role (Barreiro 2013). It is 4 times more common in females (Baikoussis 2015). These tumors are observed especially in the third-sixth decade of life.

Myxomas can generally be seen in the left atrium with a ratio of $75 \%-80 \%$, in the right atrium with $15 \%-20 \%$, and in other cardiac parts with 5\% (Kaplan 2002). Fossa ovalis was located in the left interatrial septum in 19 of our patients $(82.6 \%)$, in the right interatrial septum in 3 patients $(13.05 \%)$, and in the right atrial free wall in 1 patient $(4.35 \%)$.

Although the complaints caused by these tumors are not specific, the most common symptom is dyspnea. The most catastrophic finding is cranial incidents following peripheral emboli (He 2015). Complaints of the patients depend on the tumor size. If the tumoral structure is small, the patients can be asymptomatic, or common symptoms such as weight loss, weakness, general tiredness, and fever can be observed. Diagnosis can be made during scans of or consultations with these patients. As the tumoral structure enlarges, cardiac complaints such as dyspnea, orthopnea, pulmonary edema, hemoptysis, coughing, and fainting can be observed after blood flow restriction (Ikeda 2014). The most common symptoms in our patients were dyspnea and chest pain.

Echocardiography is the imaging method most commonly demanded for cardiac mass diagnosis (Yu 2016). Echocardiography is the imaging technique that should be primarily preferred for its noninvasive and fast applicability and for provision of information about the tumor such as the size, structure, mobility, and its relation with adjacent cardiac structures. Transesophageal echocardiography should be done in case of suspicion. Magnetic resonance imaging and 
Table 4. Patients' Operative and Postoperative Data

\begin{tabular}{lc}
\hline Variable & Data, N (23)* \\
\hline ACC time (minutes) & $23.6 \pm 15.1$ \\
Total bypass time (minutes) & $35.4 \pm 10.5$ \\
Extubation time (hours) & $2.4 \pm 1.4$ \\
Mean intensive care unit stay (days) & $1.2 \pm 1.6$ \\
Average length of stay at the hospital (days) & $5.7 \pm 2.6$ \\
AF & $3(13.05 \%)$ \\
Revision surgery & $1(4.3 \%)$ \\
Mortality & - \\
\hline
\end{tabular}

*Data given as mean \pm SD or $\mathrm{n}(\%)$.

computed tomography are also used for cardiac thrombus distinction recently (Haji 2017). Coronary angiography can also be used for accompanying coronary incidents for patients over 45 years of age.

Although there are no specific findings in laboratory examination of these tumoral structures, findings such as anemia, CRP, and erythrocyte-sedimentation increase may be observed generally. Ninety-eight patients were examined in a study by Garatti et al (Abu Abeeleh 2017), and the most common laboratory findings were high sedimentation, CRP, and anemia. Average CRP level was $18 \pm 6.8$, erythrocytesedimentation rate was $16 \pm 8.9$, and this was considered high for the patients. Cardiac rhythm disorders may be observed before and after the operation on these tumors. It may cause rhythm disorders such as blockage, atrial fibrillation ( $\mathrm{AF}$ ), and atrial flutter if it is located close to transfer pathways before the operation. Postoperative AF occurred in 3 of our patients $(13.05 \%)$, and sinus rhythm was changed by taking it under control with medical treatment.

These tumoral structures hold on to the tissue they are based on through a polyp. In microscopic terms, they have a jellylike appearance with low cellular structures scattered in the mucopolysaccharide matrix (Zheng 2013). These jellylike structures should be handled gently to prevent embolic incidents during the operation. The healthy tissue that the polypoid structure holds on to should also be resected during surgical resection. This is important for preventing relapse. We performed resection by opening the right atriotomy and the interatrial septum with aortic and bicaval cannulation under $\mathrm{CPB}$ under median sternotomy in all patients. Following the resection, pericardial patch was used in $11(47.8 \%)$ patients; and primary repair, in $12(51.2 \%)$ patients. Annuloplasty was applied because of the tricuspid-valve-annulus enlargement due to the large tumors in 2 patients (Akyol 2016). Myxoma was diagnosed in all patients, owing to the pathological examination of the tumor materials excised after the operation.

It is possible for the tumor to relapse in the early or late period following the operation. Forty-seven patients were examined in a study by (Arıcı 2015). Relapse was observed in 2 patients, owing to the 5 -year follow-ups of these patients.

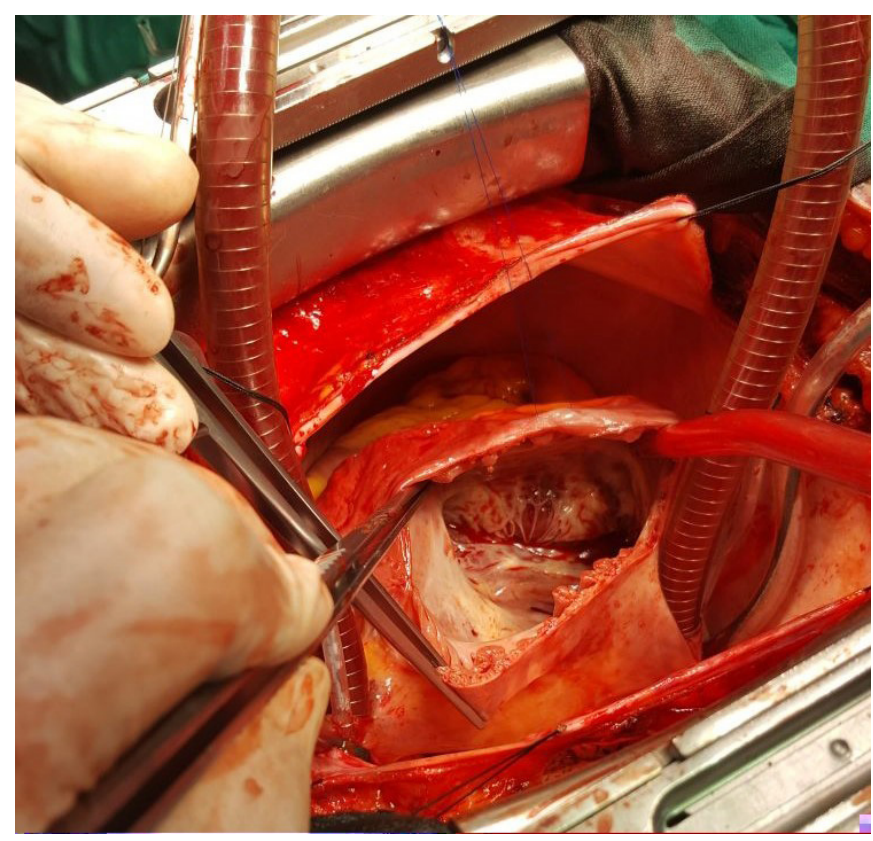

Figure 4. Tricuspid valve enlargement.

In a study by Shah et al (Shah 2015), 194 patients were examined retrospectively for 50 years. It was observed that the relapse rate increased at 10-year follow-up in young patients for small-tumor diameter and ventricle-located tumor. The most important point here is to excise the polypoid structure to which the tumor holds on, together with the healthy tissue.

In a study by Brinjikji et al (Brinjikji 2015), 47 patients were followed up for 9 years, and ischemic stroke and intracranial aneurysm were detected in a significant number of myxoma patients who had brain imaging. The possibility of intracranial bleeding, aneurysm, and cerebral metastatic disease was found higher especially in patients referring with myxoma-related embolic complications.

Although there is no direct connection between the size of the tumoral structure and the symptoms, in a series by Pinede et al (Pinede 2001) including 112 cases, it was stated that the symptoms appeared especially after the tumor was $5 \mathrm{~cm}$ or bigger.

A study showing that the softness or hardness of the tumor is effective on the symptoms of the disease was made by Rahman et al (Rahman 2015). The study was divided into 2 groups as Group 1 (Soft, $\mathrm{n}=50$ ) and Group 2 (Solid, $\mathrm{n}=18$ ). Although there were more neurological findings and $\mathrm{AF}$ in Group 1, fever, dyspnea, and cardiac failure were observed more in Group 2.

In a study by Sinimelakis et al (Siminelakis 2014), it was reported that the villous structure of myxoma surface can be related to cerebral and peripheral embolism, and flat-surfaced tumors can be observed with a coincidental and a cardiovascular finding. Again in the same study, it was emphasized that fossa ovalis should be resected completely and closed with a pericardial patch to prevent tumor relapse. For "Again in the same study," do you mean this instead: "Also, in the same study,"? 


\section{CONCLUSION}

Cardiac myxomas are the most common cardiac tumors. Although these tumoral structures have a benign character, they may have catastrophic results especially due to secondary complications such as cranial and peripheral emboli. Resection should be done with CPB in the early period after the diagnosis and operation preparations. It is important to decrease the recurrence by resecting the area that the tumor polypoid stem holds on to together with the healthy tissue and by controlling all cardiac spaces. Patients should be followed up with echocardiography every 6 months following the operation.

\section{REFERENCES}

Abu Abeeleh M, Saleh S, Alhaddad E, et al. 2017. Cardiac myxoma: clinical characteristics, surgical intervention, intra-operative challenges and outcome. Perfusion 32(8):686-90.

Akyol A, Şimşek H, Yaman M, Gur AK, Akdag S. 2016. A giant atrial myxoma with fairly atypical features. Int J Cardiovasc Acad 2(1):42-3.

Baikoussis NG, Papakonstantinou NA, Dedeilias P, et al. 2015. Cardiac tumors: a retrospective multicenter institutional study. J BUON 20(4):1115-23

Barreiro M, Renilla A, Jimenez JM, et al. 2013. Primary cardiac tumors: 32 years of experience from a Spanish tertiary surgical center. Cardivasc Pathol 22(6):424-7.

Brinjikji W, Morris JM, Brown RD, et al. 2015. Neuroimaging findings in cardiac myxoma patients: a single-center case series of 47 patients. Cerebrovasc Dis 40(1-2):35-44.

Garatti A, Nano G, Canziani A, et al. 2012. Surgical excision of cardiac myxomas: twenty years experience at a single institution. Ann Thorac Surg 93(3):825-31.

GurAK, Kaya Y, KarakurtA, Güvenç TS. 2012. Miksoma ve fibroelastomanın eşlik ettiği Carney sendromlu hasta. Dicle Med J 39(3):413-15. Turkish.

Haji K, Nasis A. 2017. Radiological characteristics of atrial myxoma in Cardiac Computed Tomography. J Cardiovasc Comput Tomogr 11(3):234-6

He D, Zhang Y, Liang Y, et al. 2015. Risk factors for embolism in cardiac myxoma: a retrospective analysis. Med Sci Monit. 21:1146-54.

Hoffmeier A, Sindermann JR, Scheld HH, Martens S. 2014. Cardiac tumors-diagnosis and surgical treatment. Dtsch Arztebl Int 111(12): 205-11

Ikeda A, Tsukada T, Konishi T, Matsuzaki K, Jikuya T, Hiramatsu Y. 2014. Right atrial myxoma with a large tumor embolus in the left pulmonary artery. J Surg Case Rep. 2014(10):rju115.

Kaplan M, Demirtaş MM, Çimen S, Gerçekoğlu H, Yapıcı F, Özler A. 2002. Kardiyak miksoma: 45 olguluk deneyim. Turkish J Thorac Cardiovasc Surg 10(1):11-14. Turkish.

Pinede L, Duhaut P, Lorre R. 2001. Clinical presentation of left atrial cardiac myxoma. A series of 112 consecutive cases. Medicine (Baltimore) 80(3):159-72.

Rahman SM, Kibria MG, Rahim AM, Hosain N, Quashem MA. 2015. Clinical presentation of left atrial myxoma in relation to anatomic and pathologic type. Cardiovasc J 8(1):19-22.

Shah IK, Dearani JA, Daly RC, et al. 2015. Cardiac myxomas: a 50-year experience with resection and analysis of risk factors for recurrence. Ann Thorac Surg 100(2):495-500.

Siminelakis S, Kakourou A, Batistatou A, et al. 2014. Thirteen years follow-up of heart myxoma operated patients: what is the appropriate surgical technique? J Thorac Dis 6(suppl 1):S32-8.

Ying L, Lin R, Gao Z, Qi J, Zhang Z, Gu W. 2016. Primary cardiac tumors in children: a center's experience. J Cardiothorac Surg 11(1): 52.

Yu L, Gu T, Shi E. 2016. Echocardiographic findings and clinical correlation with cardiac myxoma. JACC Cardiovasc Imaging 9(5):618-21.

Zheng JJ, Geng XG, Wang HC, Yan Y, Wang HY. 2013. Clinical and histopathological analysis of 66 cases with cardiac myxoma. Asian Pac J Cancer Prev 14(3): 1743-6. 